LEADERSHIP, 2(1), Desember 2020, ISSN (online) : :2715-0399 I

ISSN (Print out) : 2721-7108

Homepage : http://e-journal.staima-alhikam.ac.id/index.php/mpi

DOI : : : : $\quad$ : $\quad$ R2478/leadership.v2i1. 586

Article type : Review Article

\title{
PERAN KEPALA MADRASAH DALAM PELAKSANAAN MANAJEMEN PESERTA DIDIK DI MI NURUL YAQIN BULULAWANG MALANG
}

\author{
Aulatun Nahdiyatid Diniyah
}

STAI Ma'had Aly Al-Hikam Malang, Indonesia

\begin{abstract}
The main objective of educational institutions is the output of their students. Therefore it requires good student management as well as the role of the principal in running and managing it. This research uses a descriptive research method with a qualitative approach. The purpose of this research is to describe in real terms the implementation of student management and to know the role of the principal in the management of students at MI Nurul Yaqin Bululawang Malang. Data collection techniques include: observation, interviews and documentation. The research subjects were school principals, student staff, teachers, PPDB committee heads, students and alumni of $\mathrm{MI}$ Nurul Yaqin Bululawang Malang. The results showed that: 1) the implementation of student management at MI Nurul Yaqin Bululawang Malang was quite good. This is evidenced by implementing the stages of student management properly even though there are some that have not been implemented. 2) the role of the head of the madrasah in the implementation of student management has been carried out properly in accordance with its role as educator, manager, administrator, supervisor, leader, innovator and motivator.
\end{abstract}

Keywords: madrasah principal, student management

92 Email Addres: Aulatunnahdiyah@gmail.com

LEADERSHIP: Jurnal Mahasiswa Manajemen Pendidikan is licensed under The CC BY License (https://creativecommons.org/licenses/by-sa/4.0/ ) 
LEADERSHIP, 2(1), Desember 2020, ISSN (online) : :2715-0399 I

ISSN (Print out) : 2721-7108

Homepage : http://e-journal.staima-alhikam.ac.id/index.php/mpi

DOI : : 10.32478/leadership.v2i1. 586

Article type : Review Article

\begin{abstract}
ABSTRAK
Tujuan utama lembaga pendidikan adalah output peserta didiknya. Oleh karena itu dibutuhkan manajemen peserta didik yang baik juga peran kepala sekolah dalam menjalankan dan mengaturnya. Penelitian ini menggunakan metode penelitian deskriptif pendekatan kualitatif. Tujuan penelitian ini adalah untuk mendeskripsikan secara nyata tentang pelaksanaan manajemen peserta didik serta mengetahui peran kepala madrasah dalam pelaksanaan manajemen peserta didik di MI Nurul Yaqin Bululawang Malang. Teknik pengumpulan data meliputi: observasi, wawancara dan dokumentasi. Subjek penelitian adalah kepala sekolah, waka kesiswaan, guru, ketua panitia PPDB, siswa dan alumni MI Nurul Yaqin Bululawang Malang. Hasil penelitian menunjukkan bahwa: 1) pelaksanaan manjemen peserta didik di MI Nurul Yaqin Bululawang Malang sudah dikatakan cukup baik. Hal ini dibuktikan dengan melaksanakan tahap-tahap manajemen peserta didik dengan baik meskipun ada beberapa yang belum terlaksana. 2) peran kepala madrasah dalam pelaksanaan manajemen peserta didik sudh dijalankan dengan baik sesuai dengan perannya sebagai educator, manager, administrator, supervisor, leader, innovator dan motivator.
\end{abstract}

Kata kunci: kepala madrasah, manajemen peserta didik

\title{
A. PENDAhuluan
}

Lembaga pendidikan di Indonesia selalu berupaya untuk memperbaiki kualitas karena majunya bangsa terletak dari kualitas manusianya. Tujuan pendidikan yang paling utama adalah

LEADERSHIP, 2(1), Desember 2020, ISSN (online) : :2715-0399 I

ISSN (Print out) : 2721-7108

Homepage : http://e-journal.staima-alhikam.ac.id/index.php/mpi

DOI : : 10.32478/leadership.v2i1. 586

Article type : Review Article 
LEADERSHIP, 2(1), Desember 2020, ISSN (online) : :2715-0399 I

ISSN (Print out) : 2721-7108

Homepage : http://e-journal.staima-alhikam.ac.id/index.php/mpi

DOI : : : : $\quad$ : $\quad$ Review Article

Article type : Review Article

meningkatkan kualitas sumber daya manusia. Tidak hanya kualitas pendidik dan tenaga kependidikan yang sangat diperhatikan dalam lembaga pendidikan akan tetapi menjadikan tujuan utama dalam memperbaiki peserta didiknya. Madrasah/ Sekolah merupakan tempat yang paling memungkinkan seseorang dalam meningkatkan atau menambah pengetahuan serta tempat paling mudah untuk membina generasi muda sebagai penerus bangsa. Keberhasilan lembaga pendidikan melalui proses pembelajaran sangat dipengaruhi oleh keberhasilan peserta didik. Manajemen peserta didik adalah salah satu komponen yang sangat penting dalam sebuah lembaga pendidikan, sehingga apabila manajemen peserta didiknya baik maka mutu sekolah tersebut juga baik.

Selain manajemen peserta didik yang baik juga diperlukan peran kepala madrasah yang optimal. Kepala madrasah/ sekolah harus memahami lembaga yang dikelola dan dipimpinnya dengan kemampuan manajemen sebagai pegangan cara berfikir, mengelola dan menganalisis sekolah serta harus mampu menunjukkan upaya dalam meningkatkan output sekolah (kualitas, produktifitas, efesiensi, efektifitas dan inovasi). ${ }^{1}$ Kepala madrasah juga harus mampu memimpin madrasah dengan baik, maka setidaknya kepala sekolah harus memiliki sifat mandiri, professional, tangguh dalam kepemimpinannya dan mampu mengambil keputusan serta memiliki kemampuan manajemen yang baik. ${ }^{2}$

MI Nurul Yaqin adalah salah satu madrasah yang tepatnya terletak di Jl. Pesantren Blambangan Krebet Bululawang Kabupaten Malang. Dalam satu desa Madrasah ini adalah salah satu sekolah dari 3 sekolah dasar dan 3 madrasah ibtidaiyah. Oleh karena itu, setidaknya madrasah ini diharuskan memiliki ciri khas atau karakter sehingga tidak kalah saing dengan sekolah dan madrasah yang lain. Sehingga peran kepala madrasah sangat diperlukan dalam meningkatkan output madrasahnya. Dalam hal ini kepala madrasah harus bekerja sama

\footnotetext{
${ }^{1}$ Rusman, Manajemen Kurikulum, (Jakarta, Rajawali Pers, 2012), hal. 10

${ }^{2}$ E. Mulyasa, Pengembangan dan Implementasi Kurikulm 2013, (Bandung: Rosda Karya, 2014), Cet.4 hal. 39-40
}

94 
LEADERSHIP, 2(1), Desember 2020, ISSN (online) : :2715-0399 I

ISSN (Print out) : 2721-7108

Homepage : http://e-journal.staima-alhikam.ac.id/index.php/mpi

DOI : : : : $\quad$ : $\quad$ Review Article

Article type : Review Article

dengan manajemen peserta didik/ kesiswaan untuk mencapai tujuannya.

Berdasarkan penjelasan di atas, maka penulis mencoba untuk menjelaskan mengenai peran kepala madrasah dalam pelaksanaan manajemen peserta didik di MI Nurul Yaqin Bululawang Malang. Tujuan penelitian ini adalah untuk mendeskripsikan dengan benar tentang peran kepala madrasah dalam pelaksanaan manajemen peserta didik di MI Nurul Yaqin Bululawang Malang (1) manajemen peserta didik (2) peran kepala madrasah dalam pelaksanaan manajemen peserta didik.

\section{B. METODE PENELITIAN}

Penelitian ini menggunakan metode penelitian jenis deskripsi kualitatif yaitu penelitian yang digunakan ada dalam objek yang dialami. $^{3} \quad$ Jenis penelitian ini tergolong penelitian lapangan (Field Research). Penelitian lapangan adalah penelitian yang dilaksanakan di lokasi penelitian / di suatu tempat dimana peneliti telah memilih untuk meneliti gejala objek tersebut. ${ }^{4}$ Penelitian ini dimulai bulan Februari s/d bulan Juli 2020 dengan tempat penelitian di MI Nurul Yaqin Bululawang Malang yang tepatnya terletak di Jl. Pesantren Blambangan Krebet Bululawang Kabupaten Malang. Dalam mengumpulkan data, penulis menggunakan teknik observasi, wawancara dan dokumentasi. Setelah data terkumpul kemudian dilakukan analisis data dengan tahap sebagai

${ }^{3}$ Sugiono, Metode penelitian pendidikan pendekatan kualitatif,, kuantitatif dan R \& D (Bandung: Alfabeta 2007), hal.15

${ }^{4}$ Abdurrahman Fathoni, Metodologi Penelitian dan Teknik Penyusunan Skripsi, (Jakarta: Rineka Cipta, 2011), hal. 96

LEADERSHIP, 2(1), Desember 2020, ISSN (online) : :2715-0399 I

ISSN (Print out) : 2721-7108

Homepage : http://e-journal.staima-alhikam.ac.id/index.php/mpi

DOI : : 10.32478/leadership.v2i1. 586

Article type : Review Article 
LEADERSHIP, 2(1), Desember 2020, ISSN (online) : :2715-0399 I

ISSN (Print out) : 2721-7108

Homepage : http://e-journal.staima-alhikam.ac.id/index.php/mpi

DOI : : : : $\quad$ : $\quad$ Review Article

Article type : Review Article

berikut: 1) induksi: penulis menggambarkan data-data yang bersifat umum. 2) deduksi: penulis menjabarkan datak yang bersifat khusus menjadi data yang umum. 3) penarikan kesimpulan: setelah peneliti melakukan analisis data yang telah diperoleh, maka langkah selanjutnya yaitu penarikan kesimpulan sebagai hasil akhir. Dalam pengujian keabsahan data, peneliti menggunakan triangulasi teknik, yaitu peneliti melakukan pengecekan data dengan mengumpulkan data dari berbagai sumber.

C. LITERATURE REVIEW

\section{Pengertian Kepala Madrasah/ Sekolah}

Kepala madrasah/ sekolah dalam pendidikan adalah sebagai seorang pemimpin yang bertanggung jawab pada semua hal di madrasah. Seorang pemimpin yang mempunyai tugas sebagai penggerak terhadap semua orang yang ada dibawah kendalinya agar mereka saling bekerja sama untuk mencapai tujuan lembaga pendidikannya. Menurut E. Mulyasa (2009) kepala sekolah harus memiliki peran sebagai E.M.A.S.L.I.M untuk mencapai tujuan dan visi misinya dalam meningkatkan kualitas pendidikan. Peran tersebut adalah: 1) educator (pendidik), 2)manager (manajer), 3)administrator (administrator), 4)supervisor (pengawas), 5)leader (pemimpin), 6) innovator dan 7)motivator.

\section{Pengertian Manajemen Peserta Didik}

Menurut Oemar Hamalik manajemen adalah suatu proses yang berkenaan dengan usaha manusia yang dibantu oleh seseorang/ sumber lain dengan menggunakan metode atau cara-cara yang telah direncanakan sebelumnya agar tercapainya suatu tujuan. ${ }^{5}$ Sedangkan dalam bukunya yang berjudul manajemen berbasis sekolah, E. Mulyasa mengartikan manajemen pendidikan adalah segala sesuatu yang berhubungan dengan pengaturan semua proses pendidikan agar tercapainya tujuan pendidikan berjangka

\footnotetext{
${ }^{5}$ Oemar Hamalik, Manajemen Pengembangan Kurikulum, (Bandung: PT. Remaja Rosda Karya, 2007), hal. 28
}

96 
LEADERSHIP, 2(1), Desember 2020, ISSN (online) : :2715-0399 I

ISSN (Print out) : 2721-7108

Homepage : http://e-journal.staima-alhikam.ac.id/index.php/mpi

DOI : : : : $\quad$ : $\quad$ R2478/leadership.v2i1. 586

Article type : Review Article

pendek ataupun panjang yang sudah direncanakan dan ditetapkan sebelumya.

Peserta didik merupakan komponen penting dalam lembaga pendidikan, karena tidak ada guru jika tidak ada peserta didik begitupun sebaliknya. Karena sesungguhnya peserta didiklah yang membutuhkan pengajaran, guru hanya berusaha memenuhi kebutuhan yang ada pada peserta didik. ${ }^{6}$ Menurut ketentuan umum undang-undang RI No. 20 Tahun 2003 tentang Sistem Pendidikan Nasional, peserta didik adalah sebagian masyarakat yang berusaha untuk mengembangkan potensi melalui proses pembelajaran yang tersedia pada jalur, jenjang dan jenis pendidikan tersebut. ${ }^{7}$ Peserta didik dalam pendidikan Islam disebut dengan istilah muta'allim, mutarobbi dan muta'addib. Muta'allim adalah orang yang diajar atau oang yang sedang belajar. Mutarobbi adalah orang yang dididik, diasuh dan dipelihara. Sedangkan Muta'addib adalah orang yang diberi tata cara, sopan santun atau orang yang dididik menjadi orang yang baik dan berbudi pekerti. ${ }^{8}$

Menurut Eka Prihatin manajemen peserta didik adalah usaha mengatur peserta didik mulai dari masuk sampai keluar/ lulus

\footnotetext{
${ }^{6}$ Departemen Agama, Wawancara Tugas Guru dan Tenaga Kependidikan, (DirektoratJenderal Kelembagaan Agama Islam, 2005), hal. 47

${ }^{7}$ Republlik Indonesia, Undang-undang Republik Indonesia No. 14 Tahun 2005 tentang Guru dan Dosen \& Undang-undang Republik Indonesia No. 20 Tahun 2003 tentang sisdiknas, (Bandung: Permana, 2006), hal. 65

${ }^{8}$ Salminawati, Filsafat pendidikan Islam (Membangun Konnsep Pendidikan yang Islami), (Bandung: Citapustaka Media Perintis, 2012), hal 13
}

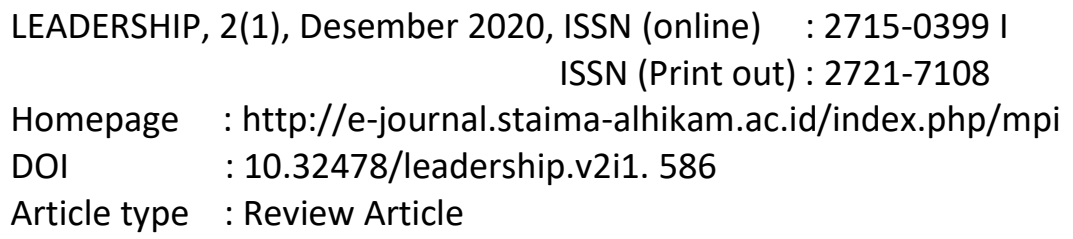


LEADERSHIP, 2(1), Desember 2020, ISSN (online) : :2715-0399 I

ISSN (Print out) : 2721-7108

Homepage : http://e-journal.staima-alhikam.ac.id/index.php/mpi

DOI : : : : $\quad$ : $\quad$ Review Article

Article type : Review Article

sekolah. ${ }^{9}$ Sedangkan menurut Mulyasa manajemen peserta didik/ manajemen kesiswaan tidak hanya pencatatan peserta didik saja akan tetapi secara operasional manajemen peserta didik dapat membantu upaya pertumbuhan dan perkembangan melalui proses pendidikan di sekolah. ${ }^{10}$

Fungsi manejemen peserta didik yakni menjadi fasilitator bagi peserta didik untuk berkembang dari dimensi individualitas, inspirasi, kemampuan, sosial, kebutuhan dan juga potensi-potensi yang dimilikinya. Tujuan manajemen peserta didik adalah mengelola kegiatan yang berhubungan dengan peserta didik/ kesiswaan untuk menunjang keefektifan mereka dalam mengikuti pembelajaran dan agar dapat mencapai tujuan lembaga pendidikan yang telah direncanakan. ${ }^{11}$

Ruang lingkup manajemen peserta didik meliputi: 1)analisis peserta didik 2)Rekruitmen/ penerimaan peserta didik 3)pengelompokan peserta didik 4)orientasi peserta didik 5)pembinaan dan pengembangan peserta didik 6)pencatatan dan pelaporan 7)kelulusan dan alumni 8)Mutasi.

\section{HASIL DAN PEMBAHASAN}

\section{Pelaksanaan Manajemen Peserta Didik}

Manajemen peserta didik di MI Nurul Yaqin Bululawang Malang dilaksanakan dengan 7 indikator manajemen peserta didik yaitu: analisis kebutuhan peserta didik, rekrutmen peserta didik, seleksi dan orientasi, pengelompokan peserta didik, pembinaan dan pengembangan peserta didik, pencatatan dan pelaporan serta kelulusan dan alumni.

a. Analisis kebutuhan peserta didik

Dalam buku manajemen Pendidikan karya Tim Dosen Administrasi Pendidikan. Bahwasannya dalam analisis peserta didik terdapat kegiatan yang harus dilakukan oleh sekolah,

\footnotetext{
${ }^{9}$ Eka Prihatin, Manajemen Peserta Didik, (Bandung: Alfabeta, 2014), hal. 4

${ }^{10} \mathrm{E}$. Mulyasa, Op. Cit, hal. 46

${ }^{11}$ Badruddin, Manajemen Peserta Didik, (Jakarta: PT. Indeks, 2014), hal. 24) 98
} 
LEADERSHIP, 2(1), Desember 2020, ISSN (online) : :2715-0399 I

ISSN (Print out) : 2721-7108

Homepage : http://e-journal.staima-alhikam.ac.id/index.php/mpi

DOI : : : : $\quad$ : $\quad$ R2478/leadership.v2i1. 586

Article type : Review Article

yaitu:121)Merencanakan jumlah peserta didik yang akan diterima 2)Menyusun program kegiatan yang berhubungan dengan peserta didik.

Dalam tahap analisa kebutuhan peserta didik, MI Nurul Yaqin mengadakan rapat bersama semua guru dan pengurus yayasan untuk menyusun program-program kegiatan yang akan dilaksanakan peserta didik. Kegiatan-kegiatan yang dapat membantu peserta didik mengembangkan diri dan memiliki pribadi yang akhlakul karimah. MI Nurul Yaqin tidak membatasi jumlah peserta didik yang masuk dikarenakan terlalu banyaknya sekolah dalam desa tersebut, sehingga yang bersekolah di MI Nurul Yaqin adalah anak-anak dari dusun Blambangan sendiri.

b. Rekrutmen peserta didik

Dalam penerimaan peserta didik baru memiliki banyak persiapan yang harus disiapkan sebelumnya, meliputi menyiapkan formulir, buku pendaftaran, waktu pendaftaran dan daftar ulang. Sehingga diperlukannya panitia khusus untuk Penerimaan Peserta Didik Baru (PPDB). ${ }^{13} \mathrm{MI}$ Nurul Yaqin memulainya dengan membentuk panitia PPDB melalui rapat bersama dan menyiapkan berbagai hal yang diperlukan ketika PPDB. Panitia akan dibagi tugas mulai dari piket jaga pendaftaran sampai peserta didik masuk dan melakukn seleksi.

\footnotetext{
12 Tim Dosen Administrasi Pendidikan, Manajemen Pendidikan, (Bandung: Alfabeta, 2011), hal. 207

${ }^{13}$ Suryo Subroto, Manajemen Pendidikan di Madrasah, (Yokyakarta: Rineka Cipta , 2004), hal. 74
}

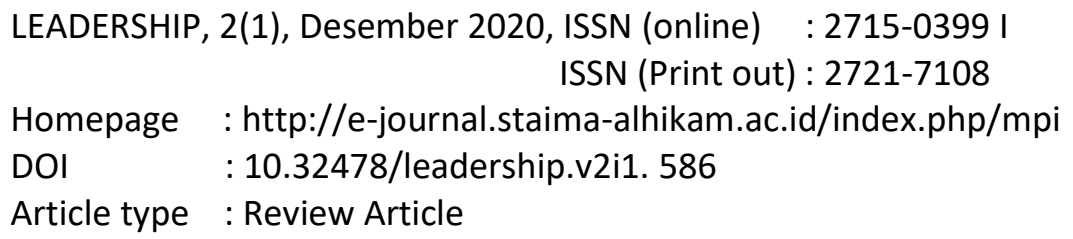


LEADERSHIP, 2(1), Desember 2020, ISSN (online) : :2715-0399 I

ISSN (Print out) : 2721-7108

Homepage : http://e-journal.staima-alhikam.ac.id/index.php/mpi

DOI : : : : $\quad$ : $\quad$ Review Article

Article type : Review Article

c. Seleksi dan orientasi

Menurut Tholib Hasan dalam bukunya Teori Dan Aplikasi Administrasi Pendidikan bahwasannya seleksi dapat dilakukan dengan 3 cara yaitu melakukan tes/ ujian, melihat hasil ujian terakhir ataupun dengan cara melakukan penelusuran bakat peserta didik. ${ }^{14} \mathrm{MI}$ Nurul Yaqin melakukan seleksi dengan menggunakan tes tulis. Seleksi yang dilakukan hanya sematamata untuk mengetahui kemampuan baca tulis peserta didik saja. Seleksi dilakukan hari pertama masuk sekolah dan diumumkan satu hari setelahnya yang langsung diberikan kepada wali murid masing-masing. Sedangkan untuk orientasinya dilakukan ketika upacara hari pertama masuk sekolah yang dilaksanakan di lapangan bersama semua jenjang mulai dari Madrasah Ibtidaiyah sampai dengan Madrasah Aliyah. Masa orientasi siswa biasanya dilakukan selama 1 minggu lamanya untuk lebih membangun kedekatan peserta didik dengan penduduk dan lingkungan sekolah.

d. Pengelompokan peserta didik

Pengelompokan peserta didik MI Nurul Yaqin dibentuk berdasarkan kemampuannya. Pengelompokan ini dinamakan Aptitude Grouping yaitu pengelompokan berdasarkan kemampuan peserta didik. ${ }^{15}$ Akan tetapi pengelompokan yang dilakukan MI Nurul Yaqin hanya untuk kelompok belajar dalam kelas saja sehingga memudahkan guru untuk mengajar/ menelateni peserta didik yang masih membutuhkan bimbingan lebih.

e. Pembinaan dan pengembangan peserta didik

Dalam pembinaan dan pengembangan peserta didik di MI Nurul Yaqin Bululawang mengadakan beberapa kegiatan tambahan. Kegiatan ekstra yang ada di luar kegiatan kurikuler.

\footnotetext{
${ }^{14}$ Tholib Hasan, Teori Dan Aplikasi Administrasi Pendidikan, (Jakarta: Studia Press), hal. 72

${ }^{15}$ Tim Dosen Administrasi Pendidikan, Manajemen Pendidikan, (Bandung: Alfabeta, 2011), hal. 211
} 
LEADERSHIP, 2(1), Desember 2020, ISSN (online) : :2715-0399 I

ISSN (Print out) : 2721-7108

Homepage : http://e-journal.staima-alhikam.ac.id/index.php/mpi

DOI : : : : $\quad$ : $\quad$ R2478/leadership.v2i1. 586

Article type : Review Article

Kegiatan tersebut seperti, kegiatan pramuka, baca Yaasiin, Istighosah, al-banjari dan juga kegiatan-kegiatan pembiasaan peserta didik yang menumbuhkan sifat Akhlaqul Karimah. Serta adanya pelayanan khusus untuk mendukung kegiatan-kegiatan tersebut, seperti musholla, kantin, koperasi, perpustakaan, lapangan bahkan asrama pondok.

f. Pencatatan dan pelaporan

Menurut M. Rifa'l dalam bukunya Manajemen Peserta Didik bahwasannya dalam pencatatan diperlukan perlengkapan, antara lain buku induk, buku klepper, buku presensi, buku mutasi, buku catatan pribadi peserta didik, daftar nilai, legger dan raport. $^{16}$ Pencatatan di MI Nurul Yaqin dimulai sejak peserta didik mendaftar yang tercatat dibuku pendaftaran, buku induk, klepper, presensi sampai buku alumni. Para guru juga selalu mencatat hasil belajar peserta didik mulai dari buku nilai, catatan pribadi siswa sampai dengan raport. Bagi peserta didik yang mutasi, maka akan dicatat dalam buku mutasi. Pelaporannya dilaporkan sesuai kebutuhan, ada yang dilaporkan setiap bulan dan setiap semester.

g. Kelulusan alumni

Kelulusan di MI Nurul Yaqin memiliki persyaratan yang berbeda dengan sekolah lain. Selain peserta didik mengikuti ujian-ujian yang telah ditetapkan, ada syarat lain yang harus dipenuhi, antara lain: hafal surah Yaasiin, do'a qunut, wirid dan doa setelah sholat juga hafal surah An-Nash sampai Ad-Dhuha.

${ }^{16}$ Muhammad Rifa'l, Manajemen Peserta Didik (Pengelolaan Peserta Didik Untuk Efektivitas Pembelajaran), (Medan: CV. Widya Puspita, 2018), hal. 19

LEADERSHIP, 2(1), Desember 2020, ISSN (online) : :2715-0399 I

ISSN (Print out) : 2721-7108

Homepage : http://e-journal.staima-alhikam.ac.id/index.php/mpi

DOI : : 10.32478/leadership.v2i1. 586

Article type : Review Article 
LEADERSHIP, 2(1), Desember 2020, ISSN (online) : :2715-0399 I

ISSN (Print out) : 2721-7108

Homepage : http://e-journal.staima-alhikam.ac.id/index.php/mpi

DOI : : : : $\quad$ : $\quad$ Review Article

Article type : Review Article

Alumni MI Nurul Yaqin tercatat di buku induk alumni. Alumni

MI Nurul Yaqin tidak memiliki organisasi alumni dari madrasah,

tetapi mereka memiliki grup di setiap angkatan. Temu alumni selalu diadakan oleh madrasah setiap satu tahun sekali bersamaan dengan acara wisuda dan kenaikan kelas.

2. Peran Kepala Madrasah Dalam Pelaksanaan Manajemen Peserta Didik

Dalam hal ini peran kepala madrasah sangat berpengaruh pada terlaksananya semua komponen manajemen peserta didik. Berikut adalah peran kepala Madrasah Ibtidaiyah Nurul Yaqin dalam pelaksanaan manajemen peserta didik:

a. Kepala Madrasah Sebagai Pendidik/ Educator

Kepala madrasah Ibtidaiyah Nurul Yaqin selalu memberikan contoh kepada semua guru dan peserta didik untuk berperilaku disiplin. Beliau tidak hanya memberikan nasihat dengan katakata saja, tetapi beliau memberikan contoh secara langsung.

b. Kepala Madrasah Sebagai Manajer

Kepala madrasah sebagai manajer bertanggung jawab menyusun program sekolah, mengkondisikan dan mengendalikan keadaan sekolah. Dalam pelaksanaan manajemen peserta didik, kepala MI Nurul Yaqin menyusun program-program seperti program penerimaan peserta didik baru kemudian memusyawarahkannya bersama semua guru dengan mengadakan rapat. Kepala madrasah membagi tugastugas kepada semua guru untuk melaksanakan programnya sesuai keputusan yang telah disepakati.

c. Kepala Madrasah Sebagai Administrator

Dalam segi administrasi, kepala madrasah memberikan perhatian dalam setiap pencatatan dan pelaporan yang telah ditentukan. Mulai dari pencatatan peserta didik masuk ke MI Nurul Yaqin sampai keluar karena mutasi/ lulus. Bapak Mahfudz selaku kepala madrasah ke-4 adalah orang yang pertama kali mengusahakan adanya buku induk di MI Nurul Yaqin. 
LEADERSHIP, 2(1), Desember 2020, ISSN (online) : :2715-0399 I

ISSN (Print out) : 2721-7108

Homepage : http://e-journal.staima-alhikam.ac.id/index.php/mpi

DOI : : : : $\quad$ : $\quad$ R2478/leadership.v2i1. 586

Article type : Review Article

d. Kepala Madrasah Sebagai Supervisor

Dalam melakukan supervisi Kepala Madrasah Ibtidaiyah Nurul Yaqin menetapkan jadwal kunjungan supervisi setiap kelas dan mengingatkan mereka pada sehari sebelum supervisi. Dalam hal kesiswaan pun kepala madrasah selalu mengawasi dan mengontrol bagian kesiswaan dalam menjalankan tugasnya. Memberikan nasihat dan bimbingan kepada semua guru bagaimana cara menghadapi pesera didik yang membutuhkan perhatian lebih.

e. Kepala Madrasah Sebagai Pemimpin/ Leader

Sesuai tugasnya sebagai pemimpin, kepala madrasah harus mampu menjaga komunikasi dengan baik kepada bawahannya dan bersikap adil serta bertanggung jawab. Sebagaimana hal tersebut, kepala MI Nurul Yaqin yakni Bapak Mahfudz Fadli, S.Pd.I. berusaha bersikap adil dalam pembagian wali kelas dan tugas mengajar. Beliau selalu menerima masukan dari para guru dan memusyawarahkan bersama agar tidak ada yang salah paham antar sesama guru.

f. Kepala Madrasah Sebagai Innovator

Sebagai innovator, kepala MI Nurul Yaqin memberikan ide-ide baru untuk para guru bagaimana cara agar para peserta didik berkembang dan berakhlakul karimah. Seperti halnya sholat dhuha setiap jam istirahat, membaca surat 5 menit setelah bel masuk dan lain-lain. Beliau juga mengusahakan sarana dan prasarana sedikit demi sedikit terlengkapi sebagai penunjang pengembangan diri siswa.

g. Kepala Madrasah sebagai Motivator

LEADERSHIP, 2(1), Desember 2020, ISSN (online) : :2715-0399 I

ISSN (Print out) : 2721-7108

Homepage : http://e-journal.staima-alhikam.ac.id/index.php/mpi

DOI : : 10.32478/leadership.v2i1. 586

Article type : Review Article 
LEADERSHIP, 2(1), Desember 2020, ISSN (online) : :2715-0399 I

ISSN (Print out) : 2721-7108

Homepage : http://e-journal.staima-alhikam.ac.id/index.php/mpi

DOI : : : : $\quad$ : $\quad$ Review Article

Article type : Review Article

Motivasi yang selalu diberikan kepala madrasah antara lain seperti:1)Motivasi pahala, 2)Motivasi penghargaan dan hukuman, 3)Mencerdaskan anak bangsa. Serta menurut kepala madrasah semua motivasi tersebut tidak akan berjalan jika tidak disertai dengan contoh kedisiplinan yang tinggi.

\section{E. KESIMPULAN}

Berdasarkan hasil penelitian dan pembahasan tentang Peran Kepala Madrasah dalam Pelaksanaan Manajemen Peserta Didik di MI Nurul Yaqin Bululawang, baik melalui wawancara, observasi dan dokumentasi. Maka penulis menyimpulkan bahwa:

1. Pelaksanaan Manajemen Peserta Didik di MI Nurul Yaqin Bululawang sudah terbilang cukup baik. Hal ini dibuktikan bahwasannya MI Nurul Yaqin Bululawang sudah melakukan tahap-tahap manajemen peserta didik yang meliputi:

a. Analisis kebutuhan peserta didik

b. Rekrutmen peserta didik

c. Seleksi dan orientasi

d. Pengelompokan peserta didik

e. Pembinaan dan pengembangan peserta didik

f. Pencatatan dan pelaporan peserta didik

g. Kelulusan dan alumni

Tahap-tahap tersebut sudah berjalan dengan baik, hanya saja ada beberapa yang masih belum terlaksana. Seperti halnya jumlah peserta yang tidak dibatasi dikarenakan jumlah peserta yang daftar hanya sedikit. Dan juga dalam pembinaan dan pengembangan peserta didik dalam hal ekstrakurikuler masih ada yang belum berjalan dengan teratur. Dalam pelaksanaan manajemen peserta didik MI Nurul Yaqin mulai dari perencanaan sampai dengan kelulusan mereka lakukan dengan bekerjasama sebagai satu tim untuk tercapainya tujuan sekolah.

2. Peran Kepala Madrasah dalam Pelaksanaan Manajemen Peserta Didik di MI Nurul Yaqin Bululawang sudah dijalankan dengan baik. Kepala madrasah sebagai educator/ pendidik selalu memberikan contoh kedisiplinan kepada semua guru dan peserta didik. Sebagai manajer, kepala madrasah selalu menggerakkan 
LEADERSHIP, 2(1), Desember 2020, ISSN (online) : :2715-0399 I

ISSN (Print out) : 2721-7108

Homepage : http://e-journal.staima-alhikam.ac.id/index.php/mpi

DOI : : : : $\quad$ : $\quad$ R2478/leadership.v2i1. 586

Article type : Review Article

semua guru untuk ikut berperan dalam melaksanakan tugas dan selalu memusyawarahkan program-program melalui rapat. Sebagai administrator, Bapak Mahfudz adalah orang yang pertama kali mengadakan pencatatan di sekolah tersebut. Jadi beliau selalu mengecek pencatatan peserta didik untuk dilaporkan secara rutin kepadanya. Sebagai supervisor, kepala madrasah menjadwalkan supervisi kunjungan kelas dilakukan 2 kali dalam satu semester setiap guru. Beliau juga melakukan supervisi kelompok dengan mengadakan rapat setiap akhir bulan untuk pergantian tema. Sebagai leader/ pemimpin, kepala madrasah mampu menjaga hubungannya dengan bawahannya secara baik. Beliau juga adil dalam pembagian tugas mengajar, karena selalu dimusyawarahkan bersama. Sebagai innovator, kepala madrasah mampu memberikan ide-ide yang baik dan professional untuk mengembangkan dan menumbuhkan sifat akhlakul karimah peserta didik. Sebagai motivator, kepala madrasah selalu memotivasi semua guru dengan beberapa hal, misalnya motivasi pahala, hukuman dan penghargaan serta beliau usahakan tidak pernah telat dalam memberikan gaji para guru agar mereka tetap semangat meskipun gajinya kecil.

LEADERSHIP, 2(1), Desember 2020, ISSN (online) : :2715-0399 I

ISSN (Print out) : 2721-7108

Homepage : http://e-journal.staima-alhikam.ac.id/index.php/mpi

DOI : : : : $\quad$ :

Article type : Review Article 
LEADERSHIP, 2(1), Desember 2020, ISSN (online) : :2715-0399 I

ISSN (Print out) : 2721-7108

Homepage : http://e-journal.staima-alhikam.ac.id/index.php/mpi

DOI : : : : $\quad$ : $\quad$ Review Article

Article type : Review Article

\section{REFERENSI}

Abdurrahman Fathoni, Metodologi Penelitian dan Teknik Penyusunan Skripsi, (Jakarta: Rineka Cipta, 2011)

Badruddin, Manajemen Peserta Didik, (Jakarta: PT. Indeks, 2014)

Departemen Agama, Wawancara Tugas Guru dan Tenaga

Kependidikan, (DirektoratJenderal Kelembagaan Agama Islam, 2005)

E. Mulyasa, Pengembangan dan Implementasi Kurikulm 2013, (Bandung: Rosda Karya, 2014), Cet.4

Eka Prihatin, Manajemen Peserta Didik, (Bandung: Alfabeta, 2014)

Muhammad Rifa'I, Manajemen Peserta Didik (Pengelolaan Peserta

Didik Untuk Efektivitas Pembelajaran), (Medan: CV. Widya Puspita, 2018)

Oemar Hamalik, Manajemen Pengembangan Kurikulum, (Bandung:

PT. Remaja Rosda Karya, 2007)

Republlik Indonesia, Undang-undang Republik Indonesia No. 14

Tahun 2005 tentang Guru dan Dosen \& Undang-undang Republik Indonesia No. 20 Tahun 2003 tentang sisdiknas, (Bandung: Permana, 2006)

Rusman, Manajemen Kurikulum, (Jakarta, Rajawali Pers, 2012)

Salminawati, Filsafat pendidikan Islam (Membangun Konnsep

Pendidikan yang Islami), (Bandung: Citapustaka Media Perintis, 2012)

Sugiono, Metode penelitian pendidikan pendekatan kualitatif,,

kuantitatif dan R \& D (Bandung: Alfabeta 2007)

Suryo Subroto, Manajemen Pendidikan di Madrasah, (Yokyakarta:

Rineka Cipta , 2004)

Tholib Hasan, Teori Dan Aplikasi Administrasi Pendidikan, (Jakarta:

Studia Press)

Tim Dosen Administrasi Pendidikan, Manajemen Pendidikan, (Bandung: Alfabeta, 2011)

Tim Dosen Administrasi Pendidikan, Manajemen Pendidikan, (Bandung: Alfabeta, 2011) 